\title{
CHROMOSOME PAIRING AND SYNAPTONEMAL COMPLEX FORMATION IN HEXAPLOID WHEAT, MONOISOSOMIC AND DIISOSOMIC FOR THE LONG ARM OF CHROMOSOME 5B
}

\author{
by
}

\author{
PREBEN BACH HOLM \\ Department of Physiology, Carlsberg Laboratory, \\ Gamle Carlsberg Vej 10, DK-2500 Copenhagen Valby
}

Keywords: Allopolyploid, homoeologues, crossing over, Triticum aestivum

\begin{abstract}
Chromosome pairing and synaptonemal complex formation have been analyzed at the ultrastructural level in spread microsporocyte nuclei of allohexaploid wheat, monoisosomic and diisosomic for the long arm of chromosome 5B. In addition spread pachytene nuclei of two Danish winter wheat cultivars, Vuka and Kraka have been analyzed. It is shown that in wheat diisosomic for the long arms of chromosome 5B synaptonemal complex formation is arrested when about $40 \%$ of the complement has synapsed. The number of lateral components involved in multiple associations at zygotene appears to be slightly lower than in euploid wheat. In wheat monoisosomic for the long arm of chromosome $5 \mathrm{~B}$ synapsis is arrested when about $55 \%$ of the complement is combined with a synaptonemal complex. As synapsis is almost complete in euploid wheat this indicates that the short arm of chromosome 5B affects the extent of synapsis. The Danish winter wheat variety Vuka has, as is the case for euploid wheat, an almost complete pairing with synaptonemal complexes. In all nuclei one or more pairing partner exchanges were identified.
\end{abstract}

\section{INTRODUCTION}

In 1966 FELDMAN reported a dosage effect of additional copies of the long arm of chromosome $5 \mathrm{~B}$ on chiasma formation in meiosis of wheat (3). Replacement of the two chromosomes $5 \mathrm{~B}$ with an isochromosome for its long arm (monoisosomic 5BL) thus resulted in a reduction in the mean chiasma frequency at metaphase I from 43.4 to 40.3 . Two copies of the isochromosome (diisosomic 5BL) resulted in a further reduction to a mean of 37.7 chiasmata per cell while the presence of three isochromosomes led to severe asynapsis, some chiasma formation between homoeologues and a reduction in chiasma frequency to about 20 chiasmata per cell. In contrast, plants triisosomic for the long arm of chromosome 5D had normal synapsis and a number of chiasmata identical to that found in euploid wheat. The effect of three isochromosomes could be phenocopied by growing diisosomic $5 \mathrm{BL}$ plants at high $\left(30^{\circ} \mathrm{C}\right)$ or low $\left(15^{\circ} \mathrm{C}\right)$ temperatures (3). Subsequent work showed that raising the dosage of the long arm from two to three, four and six resulted in a proportionate increase in the number of interlockings present at metaphase I (16). These results have led to the proposal that the $\mathrm{Ph}$ gene on the long arm of chromosome 5B acts by suppressing premeiotic associations of homologues and homoeologues. In the absence of $\mathrm{Ph}$ an association of homologues and their homoeologues is assumed, the presence of two copies 
results in a close association of homologues only while a further increase in the dosage of $\mathrm{Ph}$ is thought to result in an increasing suppression of premeiotic associations of chromosomes leading, eventually, to a random distribution of chromosomes in the premeiotic interphase nucleus when six copies of $P h$ are present $(3,4,16)$.

Ultrastructural information on chromosome pairing and synaptonemal complex formation in allohexaploid wheat is now available for wheat lacking chromosome 5B (8), or carrying just one copy of $5 \mathrm{~B}(7)$, euploid wheat $(5,6,10)$ and wheat triisosomic for the long arm of chromosome $5 \mathrm{~B}(15)$. It is the aim of the present analysis to investigate chromosome pairing and synaptonemal complex formation in allohexaploid wheat diisosomic for the long arm of chromosome $5 \mathrm{~B}$ to assess the effect on synapsis of four copies of the long arm. In addition, synapsis has been analyzed in hexaploid wheat, where the two chromosomes 5B are replaced by an isochromosome for the long arm of chromosome $5 \mathrm{~B}$ (monoisosomic $5 \mathrm{BL}$ ) to assess, by a comparison with the data on synapsis in euploid wheat, the effect of the absence of the short arms of chromosomes $5 B$. Finally, pairing and synaptonemal complex formation have been analyzed in two Danish winter wheat varieties to see if the pairing characteristics inferred from the variety Chinese Spring are representative for other wheat varieties. The significance of the results obtained in this as well as the other studies of this series (allohexaploid wheat $(5,6,7,8,10)$, trihaploid wheat (13) and wheat-rye hybrids (14)) for chromosome pairing and chiasma formation in allopolyploids is discussed in a separate paper (9).

\section{MATERIALS AND METHODS}

\subsection{Materials}

Seeds of Triticum aestivum, cv. Chinese Spring diisosomic for $5 \mathrm{BL}$ were kindly provided by Dr. E.R. Sears, University of Missouri. Some of these plants were grown in a heated glass house at $20{ }^{\circ} \mathrm{C}$. Another population of plants was grown in growth cabinets at $15{ }^{\circ} \mathrm{C} / 10{ }^{\circ} \mathrm{C}$ day/night temperatures with 16 hours light and 8 hours darkness. Two to three weeks before meiosis the plants were transferred to a Weiss growth cabinet and grown at $20^{\circ} \mathrm{C}$ day and 15 ${ }^{\circ} \mathrm{C}$ night temperatures with a 16 hour light and 8 hour darkness regime. As described in section 3.1 , some of these plants turned out to have only one isochromosome for the long arm of chromosome $5 \mathrm{~B}$. A third population of plants remained at $15^{\circ} \mathrm{C} / 10^{\circ} \mathrm{C}$ to assess the effect of temperature on meiosis in this genotype. Vernalized seedlings of the two Danish winter wheat varieties, Vuka and Kraka were obtained from Dr. SVEN B. ANDERSEN, The Royal Veterinary and Agricultural University, Copenhagen. As was the case for the other wheat genotypes they were initially grown at a $15^{\circ} \mathrm{C} / 10^{\circ} \mathrm{C}$ thermoperiod in growth cabinets, and a few weeks before meiosis transferred to a $20^{\circ} \mathrm{C} / 15^{\circ} \mathrm{C}$ thermoperiod.

\subsection{Methods}

Squashing and staining/N-banding of root tip metaphase complements, and meiotic metaphase I chromosomes, as well as the procedures for spreading and electron microscopy were performed as described previously $(6,7)$.

\section{RESULTS}

\subsection{Diisosomic 5BL wheat}

\subsubsection{Light microscopy}

The genomic constitution of wheat diisosomic for the long arm of chromosome $5 \mathrm{~B}$ was assessed by orcein squashing or N-banding of metaphase I complements in the microsporocytes and by N-banding of somatic root tip metaphases (Figures 1 and 2). As described by WISCHMANN (15) and KONG (11) the isochromosome for chromosome 5B's long arm is in root tip metaphases a very characteristic isobrachial chromosome with a completely symmetrical $\mathrm{N}$-banding pattern, each arm possessing a faint proximal band and a more prominent double band medially in the long arm (2) (see insert in Figure 2). At metaphase I, the two isochromosomes were either present as a ring bivalent (Figure 2a), or as two univalents, which usually were ring shaped due to chiasma formation between the two homologous/identical arms (Figures $1 \mathrm{a}$ and $2 \mathrm{~b}$ ). If present as univalents the isochromosomes were often lying outside the 

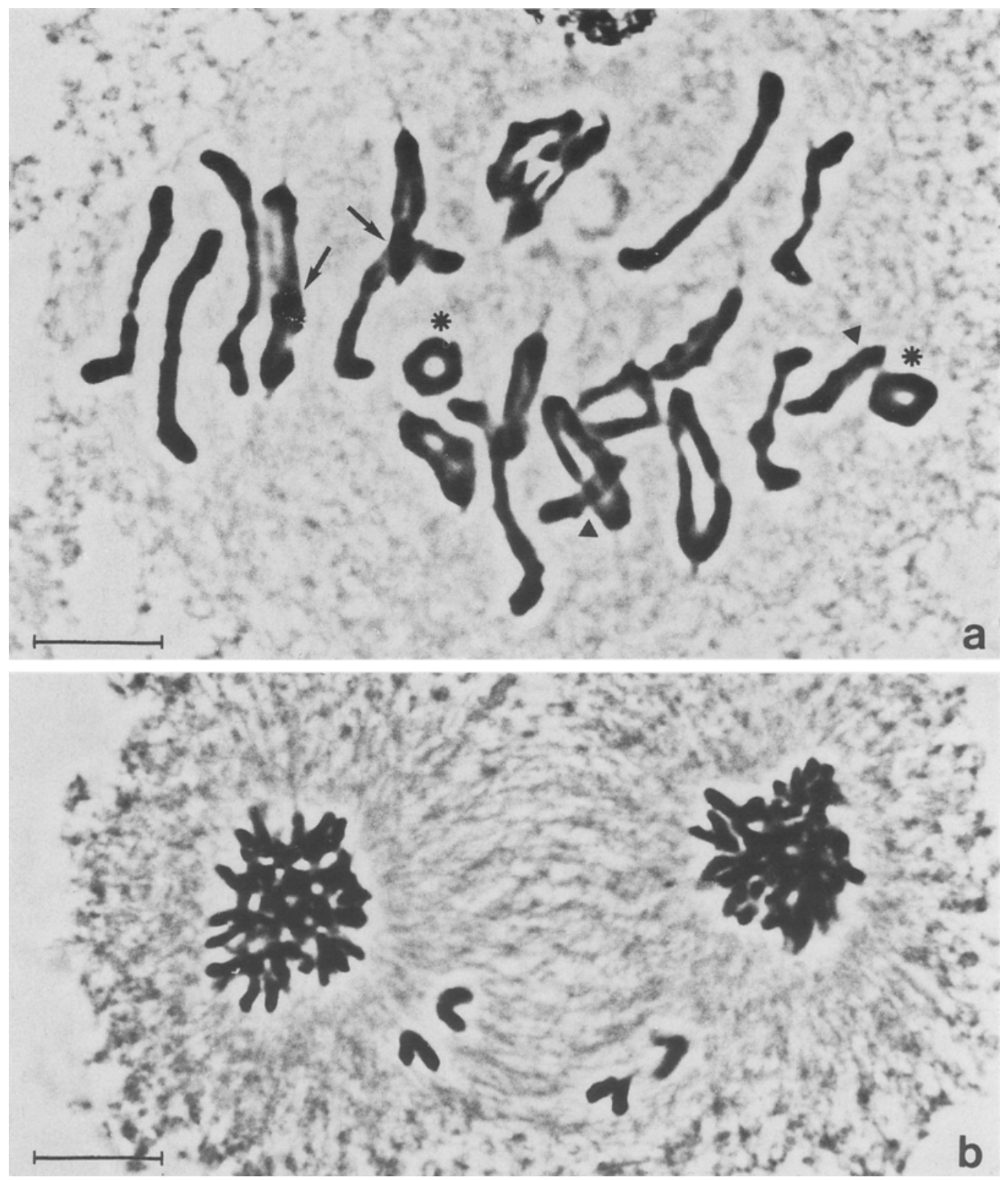

Figure 1. Figure 1a is a phase contrast photograph of an orcein stained squashed metaphase I complement of diisosomic 5BL wheat. The complement consists of 8 rod bivalents, 11 ring bivalents, two rod-shaped univalents (arrowheads) and two ring univalents (the two isochromosomes, denoted by asterisks). The two ring bivalents (arrow) and the rod and the ring bivalent marked by the other arrow are probably interlocked. In Figure $1 \mathrm{~b}$ is shown an anaphase-telophase I with four lagging chromatids. (Bar $=10 \mu \mathrm{m})$ 

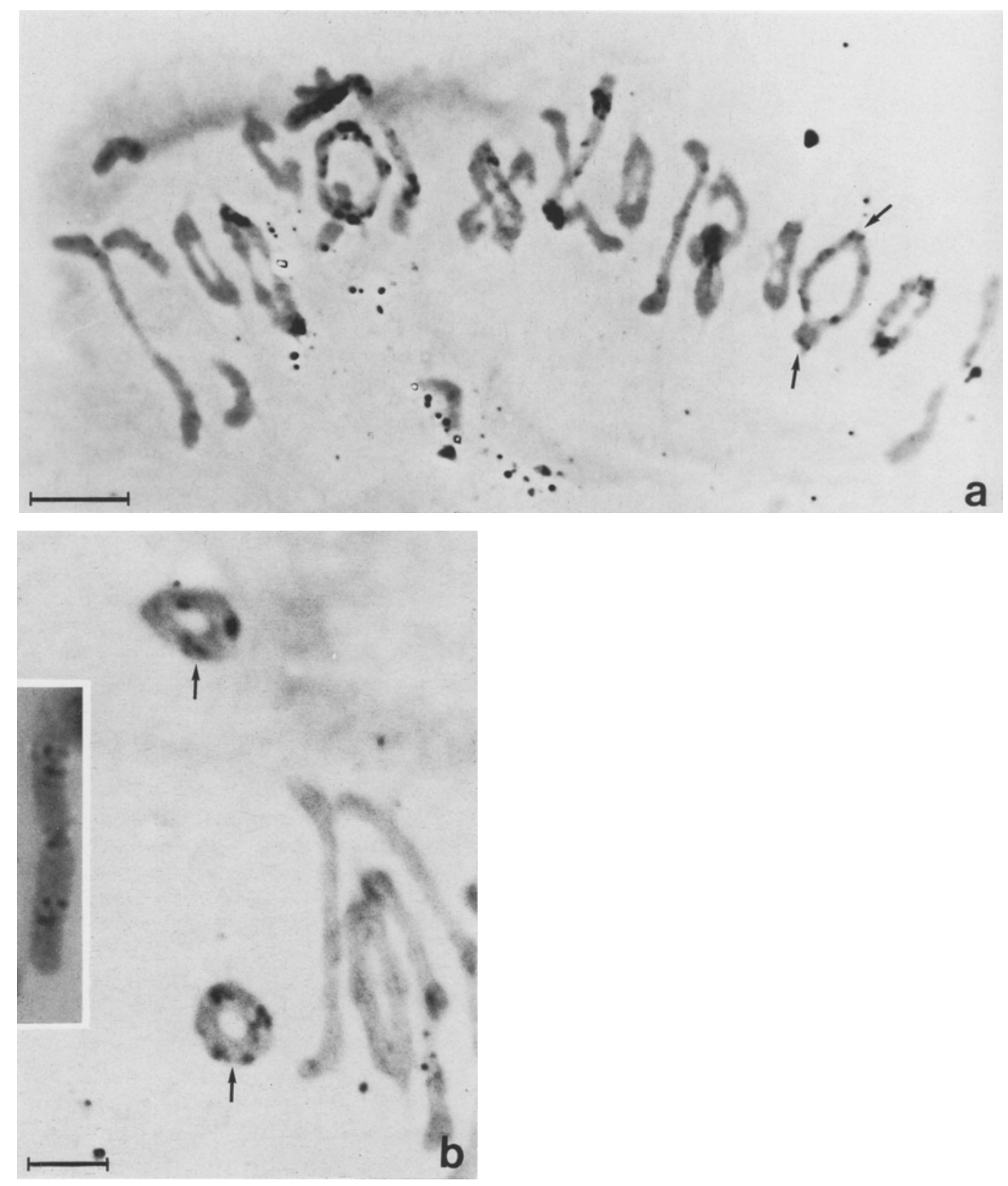

Figure 2. Figure $2 \mathrm{a}$ is a phase contrast photograph of a squashed, N-banded metaphase I complement of diisosomic $5 \mathrm{BL}$ wheat. The two isochromosomes have formed a ring bivalent (arrows). In Figure $2 b$ is shown a part of a metaphase plate, where the two isochromosomes are present as ring univalents. The arrows denote the centromere regions of the two isochromosomes. The insert shows an $\mathrm{N}$-banded isochromosome from a root tip metaphase. (Figure 2a: Bar $=10 \mu \mathrm{m}$ )

(Figure 2b: Bar $=5 \mu \mathrm{m}$ )

Figure 3. A montage of micrographs of a spread zygotene nucleus (Z7, 37\% pairing) of diisosomic 5BL wheat. A tracing of the complement of this nucleus is shown in Figure 4, and an idiogram in Figure 5. (Bar $=10 \mu \mathrm{m})$ 


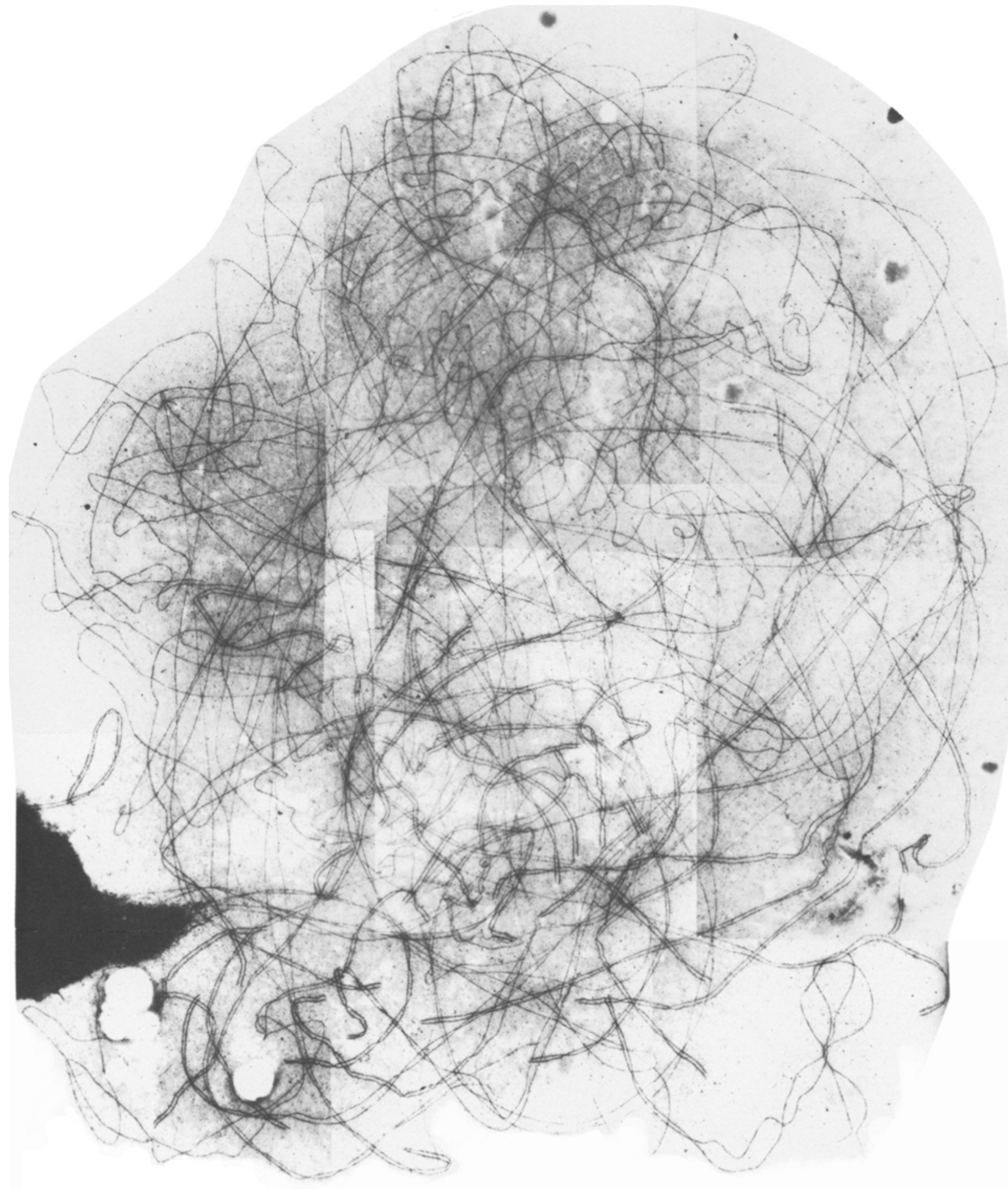




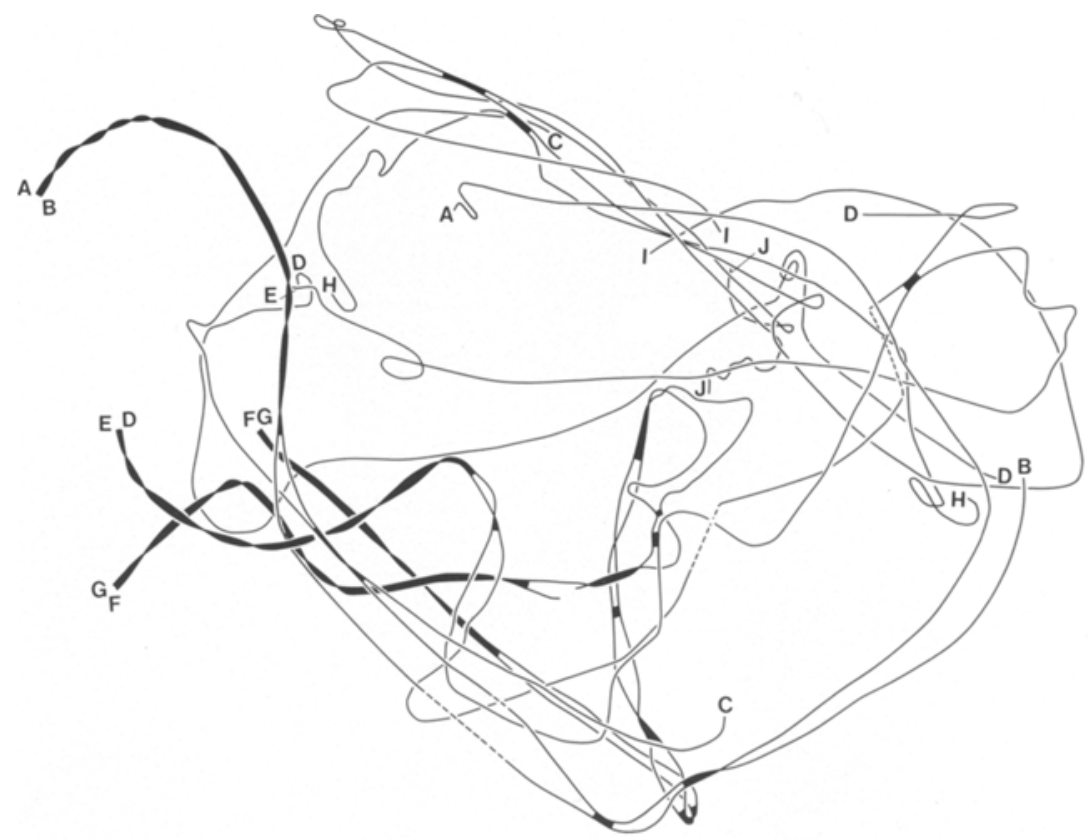

a

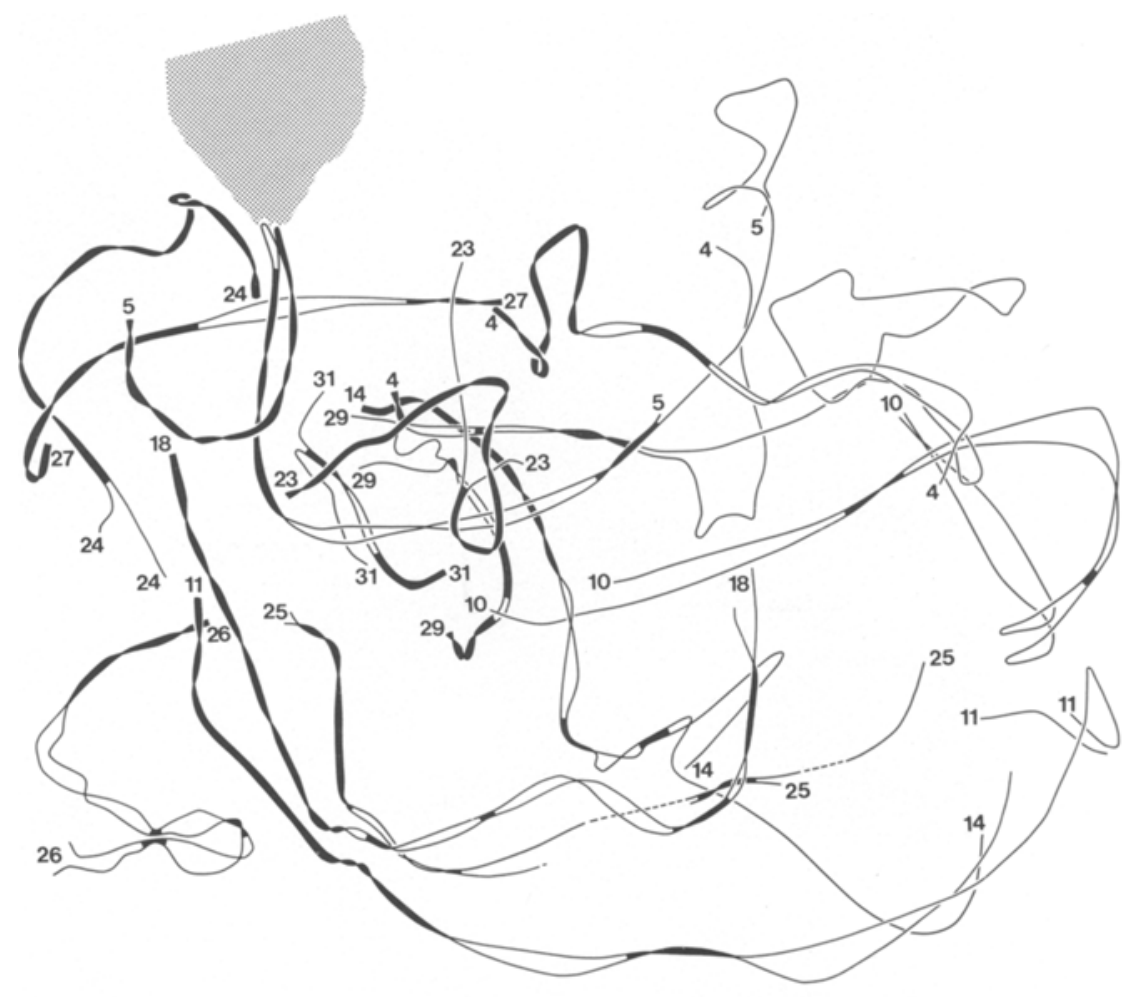

b 
P.B. Holm: Synapsis in diisosomic 5BL wheat

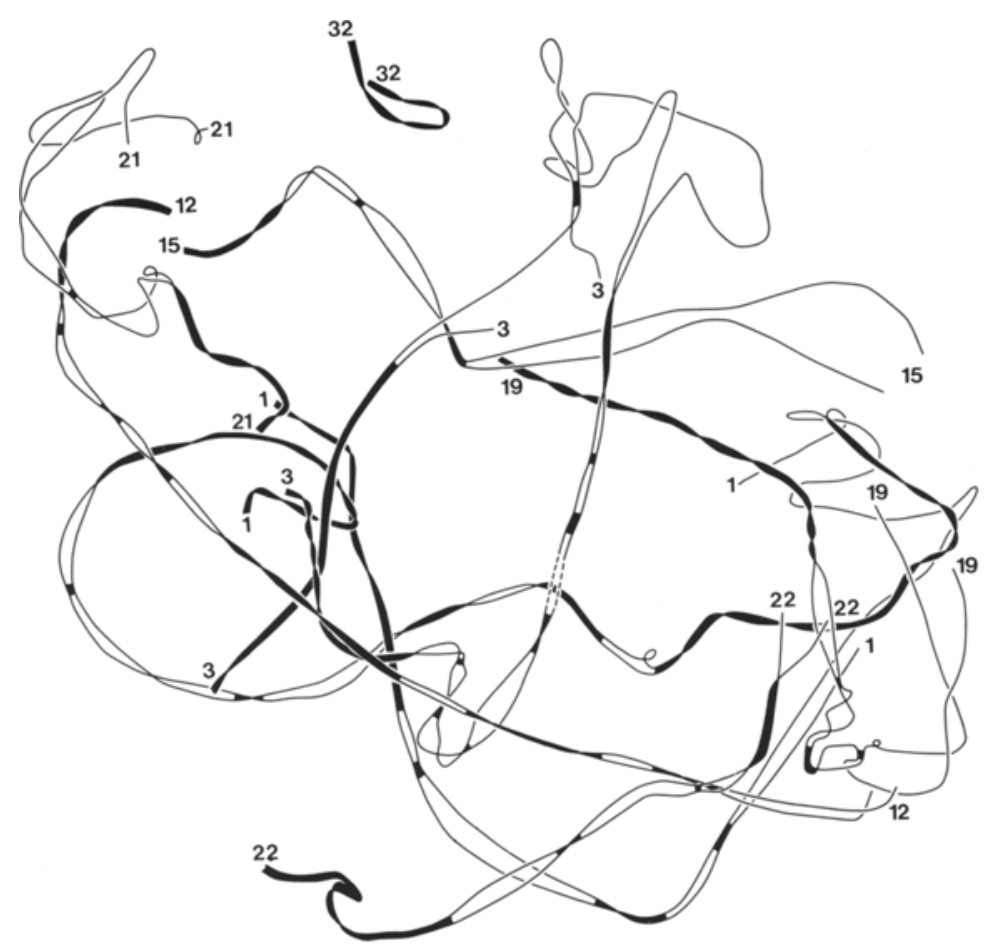

C

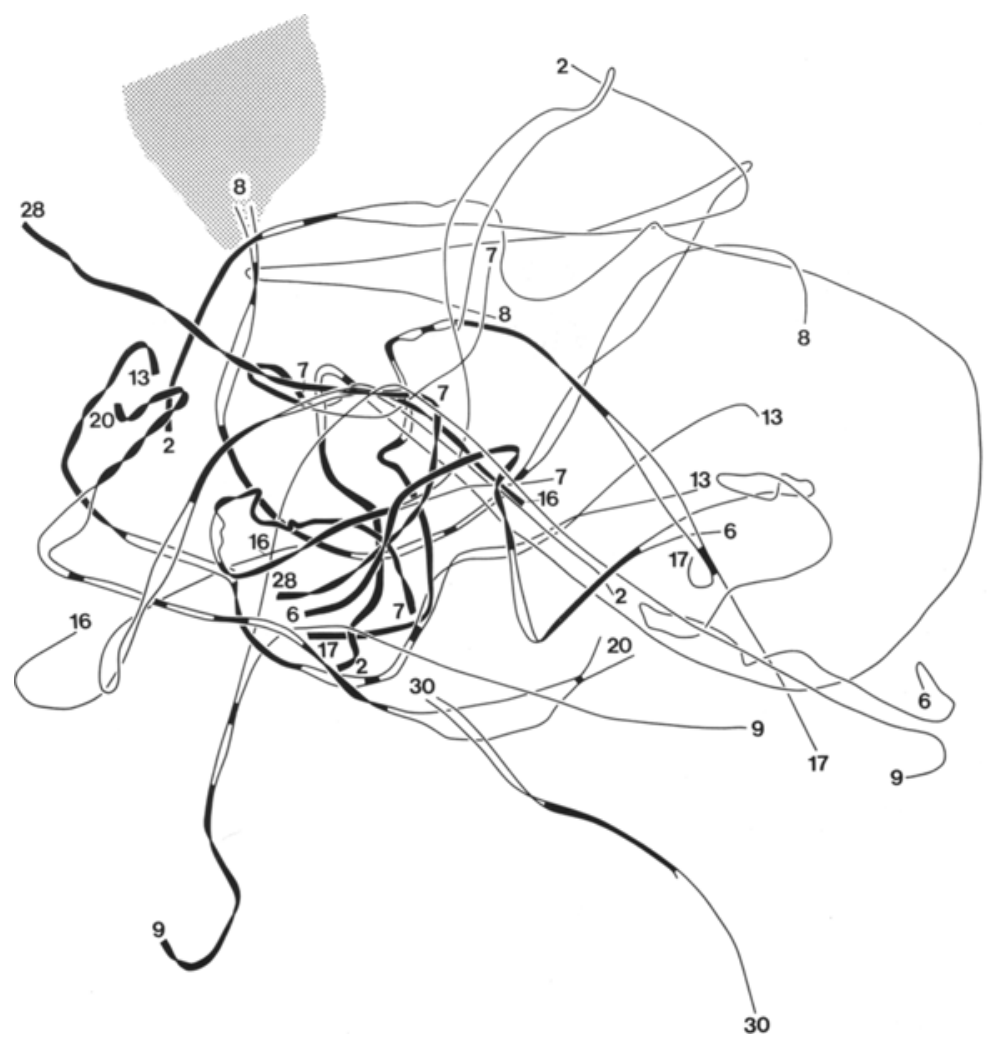


Figure 4. Tracings of the synaptonemal complex complement of a zygotene nucleus (Z7, 37\% pairing) of diisosomic 5BL wheat. The four tracings include all synaptonemal complexes of the nucleus as well as the unpaired lateral components extending from the synapsed regions. Lateral component segments, which due to breakage are not continuous with any synapsed regions, are not included in the tracings $(181 \mu \mathrm{m}$ of lateral components, $5 \%$ of the complement length). The lateral components marked by capital letters are the ones involved in multiple associations while bivalents or bivalent segments are denoted by numbers. Broken lines are used to indicate segments where lateral component continuity is difficult to recognize. The nucleolus is shown as a hatched area. The fine structure of this nucleus is shown in Figure 3 and an idiogram of the traced complement is shown in Figure 5.

metaphase plane and were lagging on the anaphase spindle. In some cases there was a precocious separation of the sister centromeres, the isochromosomes segregating as chromatids during the first meiotic division (Figure 1b).
As illustrated in Figure 1a, the metaphase I complements of diisosomic 5BL wheat are characterized by the presence of occasional univalents other than the two isochromosomes, some rod bivalents and interlocking of chromosomes

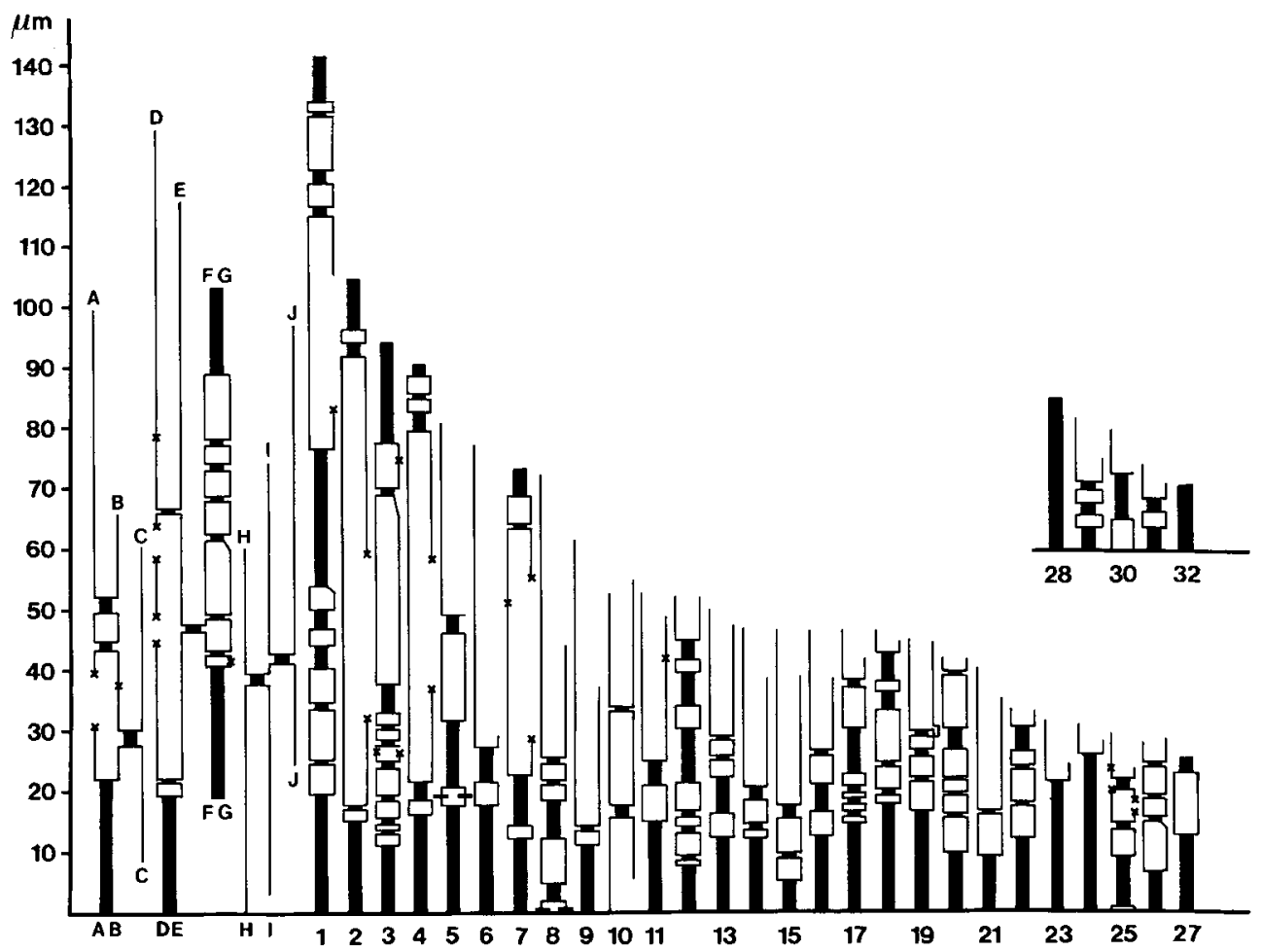

Figure 5 . An idiogram of the traced complement of a zygotene nucleus $(\mathrm{Z7}, 37 \%$ pairing) of diisosomic $5 \mathrm{BL}$ wheat. Unpaired lateral components which, due to breakage, are free in the spread nuclei are not included (181 $\mu \mathrm{m}$ of lateral component). Lateral components or lateral component segments in multiple associations are shown first and are referred to by capital letters, while partially paired bivalents or bivalent segments are denoted by numbers and arranged after decreasing length. The actual lengths of the synaptonemal complexes and the lateral components are represented by vertical lines. Breaks in lateral components are indicated by crosses and nucleolus organizing regions by crossbars. Tracings of the complement shown in the idiogram are shown in Figure 4 and a montage of micrographs of this nucleus in Figure 3. 


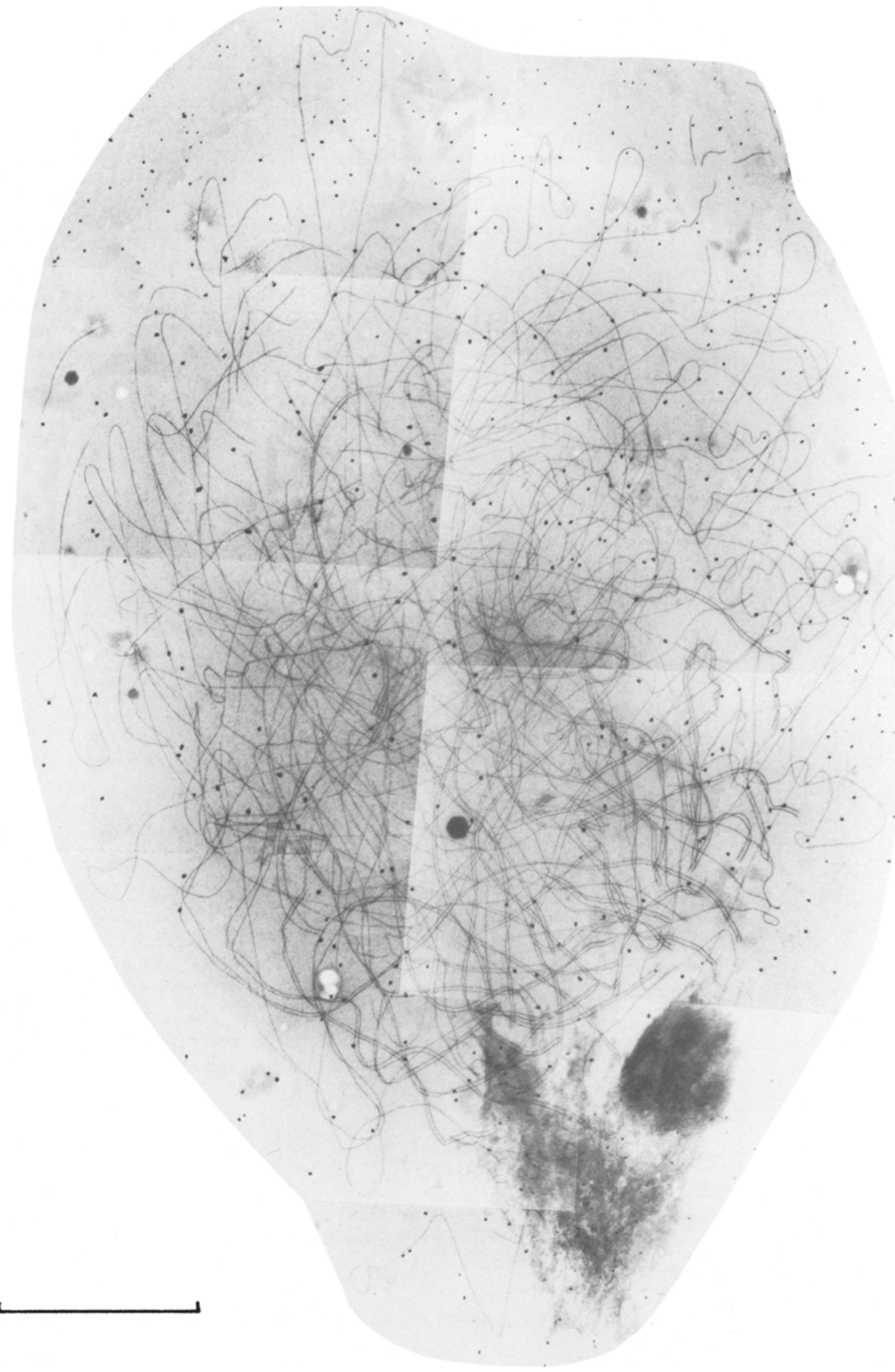


Figure 6. A montage of micrographs of a late zygotene nucleus of diisosomic $5 \mathrm{BL}$ wheat (Z2,31\% pairing). (Bar $=10 \mu \mathrm{m})$

Table I. Degree of pairing, lateral component (LC) length of one complement $(1 / 2 \mathrm{LC}$ length) and the number of lateral components or lateral component fragments involved in multiple associations in seven zygotene nuclei of wheat diisosomic for the long arm of chromosome $5 \mathrm{~B}$. The number of multiple associations in parentheses are switch back associations of type II (see section 3.1.2 for explanation). Data for early-mid zygotene nuclei of euploid wheat are included for comparison (7). s.d., standard deviation.

\begin{tabular}{lllll}
\hline $\begin{array}{l}\text { Nucleus } \\
\text { number }\end{array}$ & \% pairing & $\begin{array}{l}1 / 2 \text { LC length } \\
\mu \mathrm{m}\end{array}$ & $\begin{array}{l}\text { Number of LC's in } \\
\text { multiple associations }\end{array}$ \\
\hline 5 & 22 & 1693 & 5 & $(0)$ \\
4 & 25 & 1952 & 4 & $(4)$ \\
2 & 31 & 1786 & 6 & $(0)$ \\
6 & 31 & 1786 & 5 & $(3)$ \\
3 & 35 & 2340 & 0 & $(0)$ \\
1 & 36 & 2104 & 15 & $(0)$ \\
7 & 37 & 1922 & 10 & $(10)$ \\
\hline Mean \pm s.d. & $31 \pm 6$ & $1940 \pm 222$ & $6 \pm 5(2 \pm 4)$ \\
\hline Euploid wheat & $39 \pm 7$ & & & \\
Mean \pm s.d. & & $1984 \pm 342$ & & \\
\hline
\end{tabular}

and bivalents, whereas multivalents were not seen. Analysis of 25 metaphase I complements revealed a mean number of 2.4 univalents (including the isochromosomes), 5.2 rod bivalents and 14.5 ring bivalents per cell, the mean number of chiasmata being 36 (assuming that only one chiasma had formed in a rod bivalent or a ring univalent and two in a ring bivalent). These results are basically similar to those reported by FELDMAN (3) who found a mean number of 1.14 univalents, 4.30 rod bivalents and 16.13 ring bivalents, the mean number of chiasmata being 37.70, while RILEY et al. (12) found a mean of 34 chiasmata per cell, the mean number of univalents and bivalents being 3.5 and 19.3.

\subsubsection{Electron microscopy}

The results presented below were obtained from spread microsporocytes of two plants grown in a growth cabinet at $20^{\circ} \mathrm{C} / 15{ }^{\circ} \mathrm{C}$. Several other wheat plants diisosomic for $5 \mathrm{BL}$, including plants grown in the glass house, were also analyzed, the results obtained being the same as those from the two plants referred to above.

The initiation of chromosome pairing and synaptonemal complex formation is, as in all the other wheat genotypes investigated so far, accompanied by a congression of the telomeres to a limited part of the nucleus. The nuclear envelope cannot be seen in the preparation, but

Figure 7. A montage of micrographs of a spread early-mid diplotene nucleus of diisosomic 5BL wheat. (Bar $=10$ $\mu \mathrm{m})$ 


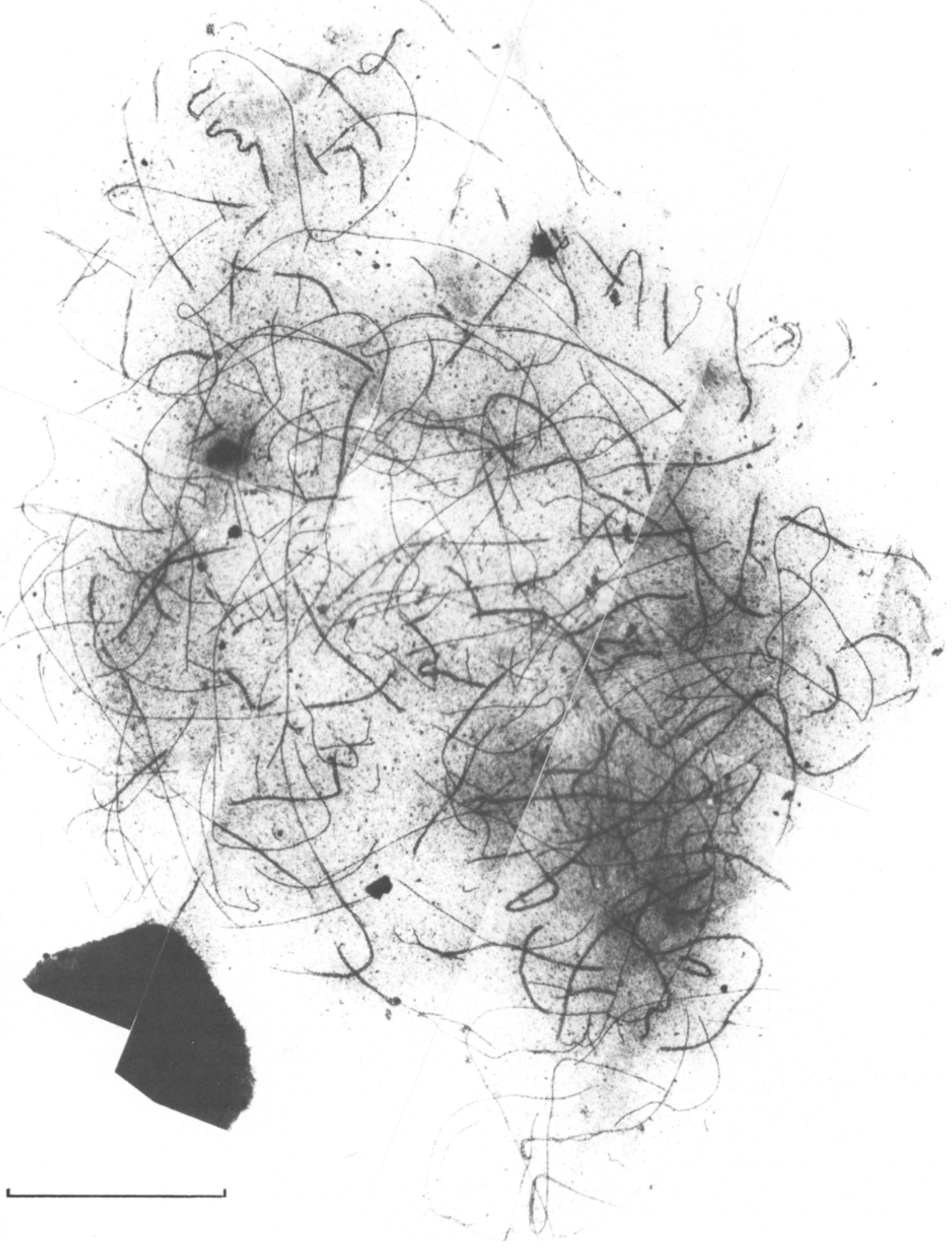


Table II. Synaptonemal complex (SC) length, the lateral component (LC) length of one complement $\left({ }^{1} / 2 \mathrm{LC}\right.$ length) and degree of pairing in 6 early diplotene (ED) nuclei of wheat diisosomic for the long arm of chromosome $5 \mathrm{~B}$ grown at $20^{\circ} \mathrm{C} / 15^{\circ} \mathrm{C}$. s.d., standard deviation.

\begin{tabular}{llll}
\hline $\begin{array}{l}\text { Nucleus } \\
\text { number }\end{array}$ & $\begin{array}{l}\text { SC length } \\
\mu \mathrm{m}\end{array}$ & $\begin{array}{l}1 / 2 \text { LC length } \\
\mu \mathrm{m}\end{array}$ & $\begin{array}{l}\% \\
\text { Pairing }\end{array}$ \\
\hline ED 1 & 547 & 1479 & 37 \\
ED 2 & 655 & 1715 & 38 \\
ED 3 & 458 & 1798 & 25 \\
ED 4 & 838 & 1492 & 56 \\
ED 5 & 988 & 1953 & 51 \\
ED 6 & 577 & 1772 & 33 \\
\hline Mean \pm s.d. & $677 \pm 199$ & $1702 \pm 185$ & $40 \pm 12$ \\
\hline
\end{tabular}

as is the case in virtually all other organisms investigated so far by serial sectioning and three dimensional reconstruction, including euploid wheat $(5,10)$ and wheat triisosomic for the long arm of chromosome $5 \mathrm{~B}(15)$, the telomeres are probably anchored to the inner membrane of the nuclear envelope. Pairing and synaptonemal complex formation appear to proceed as reported for the other wheat genotypes, being primarily initiated distally but with several regions of interstitial initiation.

The montage of micrographs in Figure 3 illustrates the morphology of a nucleus of diisosomic 5BL wheat at zygotene with $37 \%$ pairing. Tracings of this nucleus are shown in Figure 4 and an idiogram of the traced complement in Figure 5. Complete tracings of the entire complement of wheat are seldom possible at early zygotene due to lateral component breakage and intertwining of lateral components $(6,7)$. The tracings of the zygotene nuclei are, therefore, limited to the synaptonemal complexes and to the unpaired lateral components extending from the synaptonemal complexes until lateral component continuity is lost due to breakage or entanglement with other lateral components.

The quantitative analysis comprised tracing and measurement of lateral component length from seven zygotene nuclei (Table I). The mean degree of synapsis in these nuclei was $31 \%$ with a range from $22 \%$ to $37 \%$ pairing. All of these nuclei had a distinct bouquet, and the nuclei were often rather compact. A subdivision of the zygotene stage has not been attempted and the arrangement of the nuclei after increasing degree of synapsis in Table I may, therefore, not

Table III. Synaptonemal complex (SC) length, the lateral component (LC) length of one complement $\left(^{1} / 2\right.$ LC length) and degree of pairing in 7 early diplotene (ED) nuclei of wheat diisosomic for the long arm of chromosome 5B grown at $15^{\circ} \mathrm{C} / 10^{\circ} \mathrm{C}$. s.d., standard deviation.

\begin{tabular}{llll}
\hline $\begin{array}{l}\text { Nucleus } \\
\text { number }\end{array}$ & $\begin{array}{l}\text { SC length } \\
\mu \mathrm{m}\end{array}$ & $\begin{array}{l}1 / 2 \mathrm{LC} \text { length } \\
\mu \mathrm{m}\end{array}$ & $\begin{array}{l}\% \\
\text { Pairing }\end{array}$ \\
\hline ED 1 & 886 & 2374 & 37 \\
ED 2 & 1067 & 1872 & 57 \\
ED 3 & 382 & 1320 & 29 \\
ED 4 & 409 & 1424 & 29 \\
ED 5 & 436 & 1509 & 29 \\
ED 6 & 731 & 2309 & 32 \\
ED 7 & 580 & 1391 & 42 \\
\hline Mean \pm s.d. & $640 \pm 261$ & $1743 \pm 446$ & $36 \pm 10$ \\
\hline
\end{tabular}


necessarily reflect a developmental sequence. Some of the nuclei showed some signs of fragmentation of the unpaired lateral components (Figure 6). It is considered likely that this reflects a late stage of development of the nuclei, possibly signifying the initiation of lateral component degradation at early diplotene.

Meiosis in diisosomic 5BL wheat appears to differ in some respects from that observed in euploid wheat. The nuclei are more difficult to spread properly than the euploid nuclei, and the spread nuclei have often a dense appearance with a compact bouquet. Secondly, the zygotene stage appears to be longer in this genotype than in euploid wheat, as zygotene-like stages, often with fragmented lateral components, are present in anthers of a length $(1.5 \mathrm{~mm})$ where one finds the diplotene and metaphase I stages in euploid or monosomic $5 \mathrm{~B}$ wheat. As described below pairing and synaptonemal complex formation are arrested in the diisosomic 5BL genotype and the nuclei apparently remain in the zygotene stage until the diplotene stage is initiated. In nullisomic 5B, monosomic 5B and euploid wheat a pachytene stage can be identified not only by the near completion of synapsis as observed in the two latter genotypes, but also by a change in nuclear organization, where the telomeres are distributed much more evenly throughout the nuclei. Furthermore, the lateral component complement contracts to about two-thirds of its length at mid zygotene and the outline of the spread nuclei changes from circular to elongated-irregular. Nuclei with these characteristics were not seen in diisosomic 5B wheat and have not been found in wheat triisosomic for the long arm of chromosome $5 \mathrm{~B}$ either (15).

The mean number of lateral components or lateral component fragments involved in multiple associations amounted to a mean of six per nucleus in the seven zygotene nuclei analyzed. A mean of two lateral components was involved in associations referred to as type II, i.e. associations where a lateral component of a partially paired bivalent has synapsed over a short distance, $0.5-1.0 \mu \mathrm{m}$, with a univalent lateral component or another partially synapsed bivalent and then switches back to the original partner. All the multiple associations shown in the idio- gram in Figure 5 are thus type II associations.

Table I also includes data for euploid wheat at a similar stage of pairing (39\%). It is apparent that the number of lateral components in multiple associations is roughly the same in the two genotypes ( 8 lateral components versus 6 ). It should be noted though that whereas all multiple associations in euploid wheat reflect a pairing and synaptonemal complex formation between chromosomes that are not homologous, this is not necessarily the case in wheat diisosomic for 5BL. As the chromosome bouquet is established the four homologous/identical arms of the two isochromosomes are brought into proximity and during synapsis pairing and synaptonemal complex formation may proceed readily between any combination of the four chromosome arms. It has not been possible in any of the nuclei to identify the two isochromosomes but a substantial part of the multiple associations observed may reflect exchanges of pairing partners between the four arms of the two isochromosomes. Hence, the frequency of pairing partner exchange between chromosomes that are not homologous may in fact be lower in diisosomic $5 \mathrm{~B}$ wheat than in euploid wheat.

The survey micrographs in Figure 7 show the fine structure of an early-mid diplotene nucleus where the degradation of the lateral components and synaptonemal complexes is in progress. At the beginning of early diplotene the nuclei still possess the bouquet configuration, which first appears to resolve during diplotene. The mean degree of pairing found in six nuclei, assigned to the beginning of diplotene, amounted to $40 \%$, with a range from $25 \%$ to $56 \%$ (Table II).

As described in section 2.1, a second population of diisosomic 5BL plants was grown at 15 ${ }^{\circ} \mathrm{C} / 10^{\circ} \mathrm{C}$ and the microsporocytes processed as for the material grown at $20^{\circ} \mathrm{C} / 15^{\circ} \mathrm{C}$. This study was inspired by the observation that when diisosomic $5 \mathrm{BL}$ plants are grown at $15^{\circ} \mathrm{C}$, there is a reduction in chiasma frequency and some chiasma formation between homoeologues similar to that found in triisosomic 5BL wheat $(3,12)$. The zygotene stages of this material turned out to be very difficult to analyze, which is also the case for euploid and monosomic $5 \mathrm{~B}$ wheat grown at this temperature, as very few and poorly preserved nuclei were present in the spreads. A major 
reason for this difference appears to be changes in the composition of the walls and the cells of the microsporocytes, since upon maceration the extruded nucleus, the cytoplasm and the broken walls tended to stick together to a much higher degree than observed in material grown at 20 ${ }^{\circ} \mathrm{C} / 15^{\circ} \mathrm{C}$. For these reasons only the extent of synapsis achieved at the beginning of diplotene was measured. On the average $36 \%$ of the complement has synapsed in the seven nuclei, which is very similar to the $40 \%$ observed in the plants grown at $20{ }^{\circ} \mathrm{C} / 15^{\circ} \mathrm{C}$ (Table III). The mean lengths of the complements of the two populations were also very similar $(1702 \mu \mathrm{m}$ at $20^{\circ} \mathrm{C} / 15^{\circ} \mathrm{C}$ versus $1743 \mu \mathrm{m}$ at $15^{\circ} \mathrm{C} / 10^{\circ} \mathrm{C}$ ). Likewise, light microscopic studies of squashed microsporocytes did not suggest any major difference in the organization of the metaphase I complement.

\subsection{Monoisosomic $5 B L$ wheat}

\subsubsection{Light microscopy}

Two plants carrying a single copy of an isochromosome for the long arm of chromosome 5B were analyzed. One of these plants was identified among the progeny of selfed monosomic 5B wheat (7) and the isochromosome had accordingly arisen de novo by fission of chromosome 5B's centromere followed by union of the broken centromeric ends of the two sister chromatids of the long arm. All the quantitative data reported below are from analyses of this plant. Another plant, monoisosomic for 5BL, appeared among the progeny of selfed diisosomic 5BL. Light microscopical studies of metaphase

I, as well as electron microscopical analyses of spread microsporocytes, did not reveal any differences between these two plants.

At metaphase $\mathrm{I}$ in the monoisosomic $5 \mathrm{BL}$ plants the complement consisted of a univalent and 20 bivalents. The univalent was almost invariably present as a ring and in 25 metaphases analysed there was a mean of 2.5 rod bivalents and 17.5 ring bivalents (Figure 8a). Multivalents were not found. $\mathrm{N}$-banding of the metaphase I complements revealed that the ring univalent indeed was an isochromosome for the long arm of chromosome 5B, being isobrachial and possessing the characteristic banding pattern of the long arm $(2,11,15)$, i.e. a faint proximal band and a more distinct double band in the middle of the arm (Figure 8b).

\subsubsection{Electron microscopy}

The study of monoisosomic 5B wheat was primarily addressed at estimating the extent of synapsis achieved in this genotype. A detailed study of the frequency of pairing partner exchange in monoisosomic 5BL wheat was not performed, but tracing of zygotene nuclei suggested that it appeared to have as few exchanges as euploid wheat.

The analysis comprised a study of five late zygotene nuclei, two pachytene nuclei and four early diplotene nuclei. A survey micrograph of a pachytene nucleus is shown in Figure 9. In this genotype the bouquet configuration resolves at the end of zygotene as in euploid wheat and nuclei with the morphological characteristics of pachytene nuclei in euploid wheat were also found. In contrast to the situation in disosomic $5 \mathrm{BL}$ wheat, the isochromosome could be identified in some of the nuclei as a large foldback paired hairpin structure (Figure 10).

In this genotype synaptonemal complex formation is also arrested. On the average $56 \%$ of the complement has synapsed in the five late zygotene nuclei, while the mean degree of synapsis at pachytene and early diplotene in the six nuclei analyzed amounted to $53 \%$ with a range of $37 \%$ to $67 \%$ (Table IV). Since synapsis in euploid wheat is almost complete $(85 \%$ in nuclei at early diplotene and $97 \%$ in pachytene nuclei selected for an almost complete pairing (6)), it can be concluded that the absence of the short arms of chromosome $5 \mathrm{~B}$ results in a decrease in the degree of synapsis from about $90 \%$ to $56 \%$.

\subsection{Chromosome pairing in winter wheat}

The analyses of the two Danish winter wheat varieties, Vuka and Kraka, both of them being pure lines, were performed to assess whether the characteristics of chromosome pairing in euploid wheat cv. Chinese Spring, i.e. an almost complete synapsis, a short pachytene stage, and regular exchange of pairing partners during 

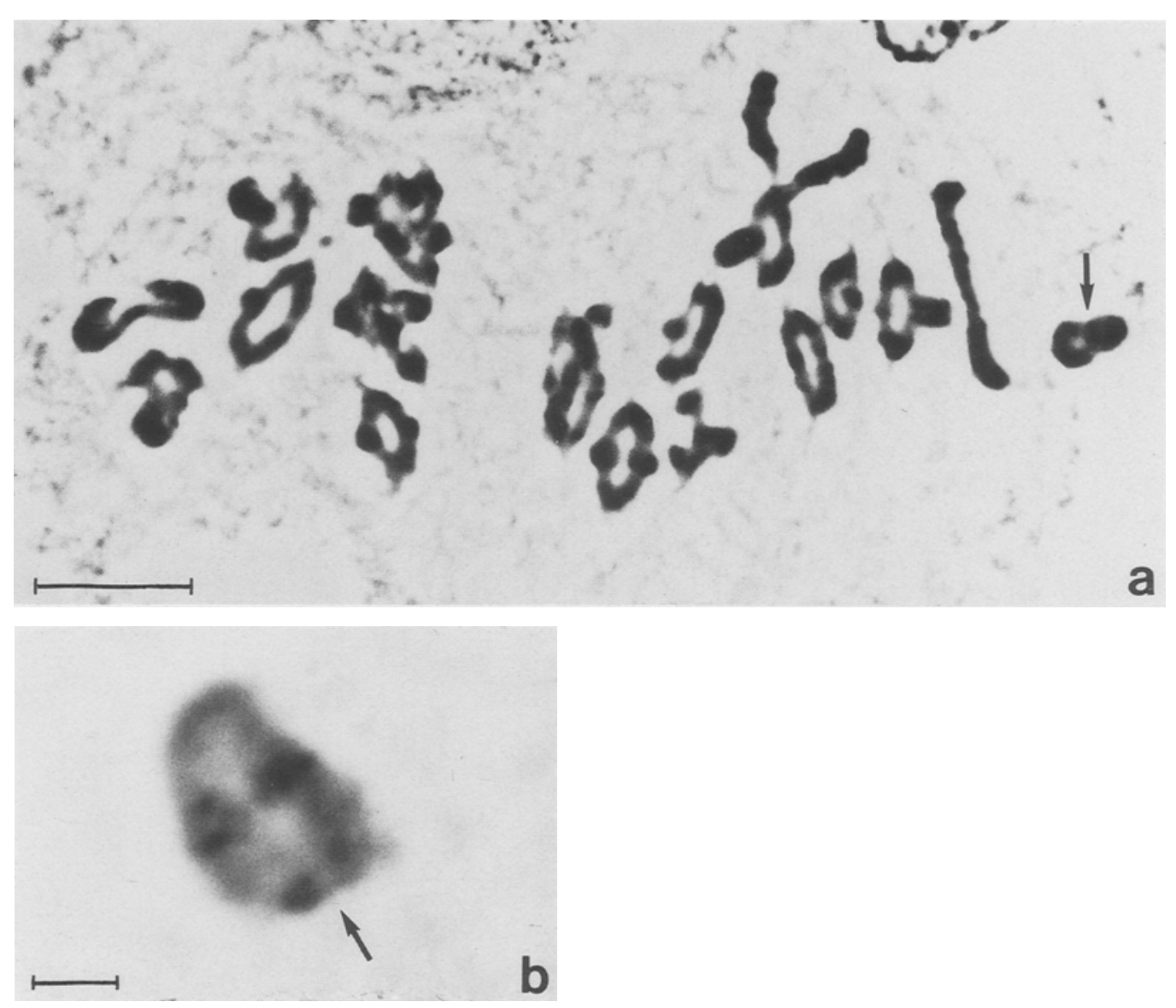

Figure 8. Figure 8a is a phase contrast photograph of a squashed, orcein stained metaphase I of monoisosomic 5BL wheat. The complement consists of 20 bivalents ( 17 ring bivalents and three rod bivalents) and one ring univalent, the isochromosome for the long arm of chromosome 5B (arrow). In Figure $8 \mathrm{~b}$ is shown a high magnification of an $\mathrm{N}$-banded isochromosome from a metaphase complement. The arrow denotes the centromere, located between the proximal band of either arm (see also Figure 2).

(Figure 8a: $\mathrm{Bar}=10 \mu \mathrm{m}$ )

(Figure 8b: Bar $=2 \mu \mathrm{m}$ )

zygotene, were shared by other wheat varieties or only characteristic for the cultivar Chinese Spring.

Spreading and light and electron microscopic studies of a large number of microsporocytes of the two winter wheat varieties did not indicate any major differences in the timing of meiosis or synaptic behaviour compared to that observed in euploid Chinese Spring. It cannot be excluded that the pachytene stage is slightly longer than in

Figure 9. A montage of micrographs showing a spread pachytene nucleus of monoisosomic 5BL wheat. $($ Bar $=10$ $\mu \mathrm{m})$ 


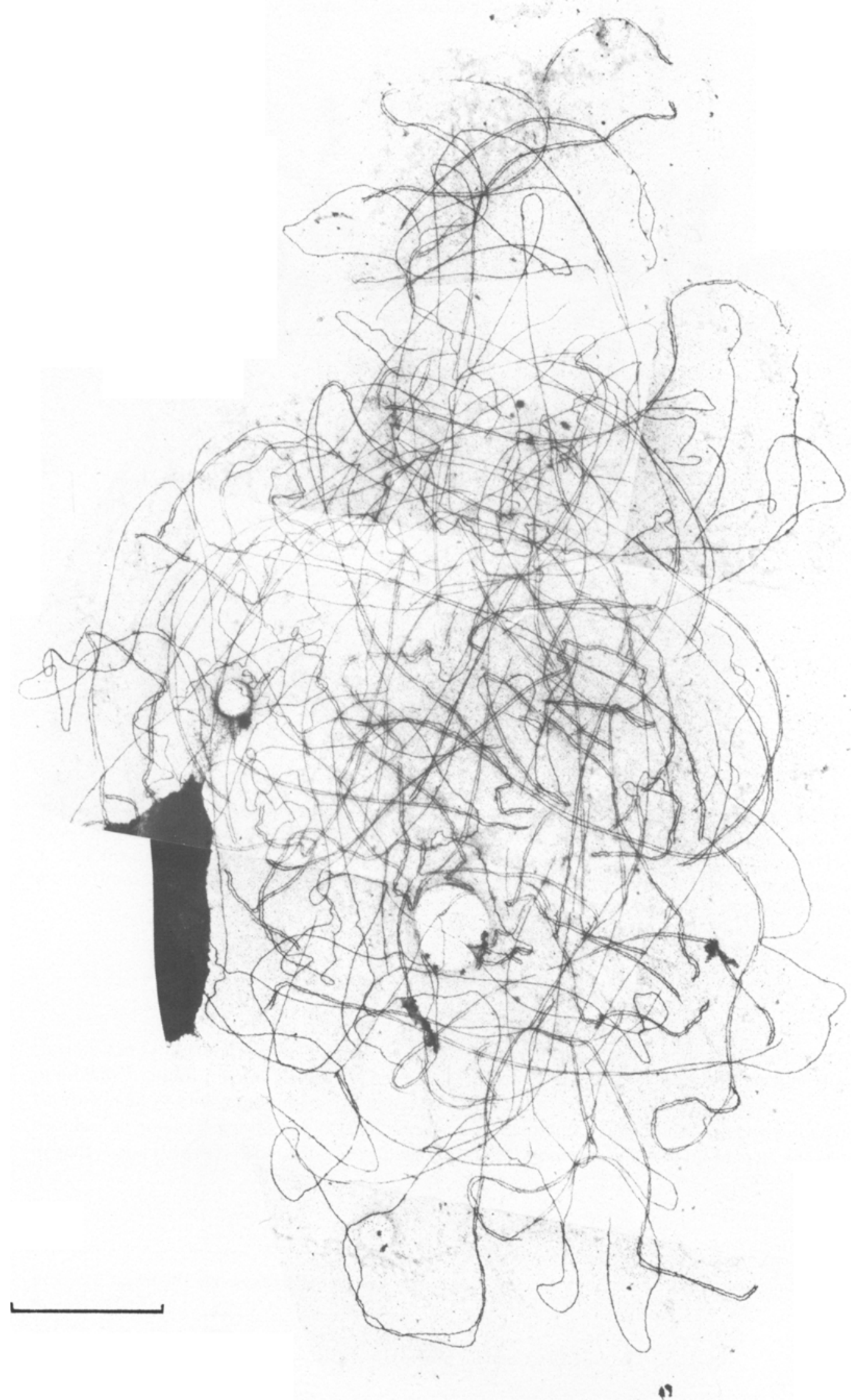




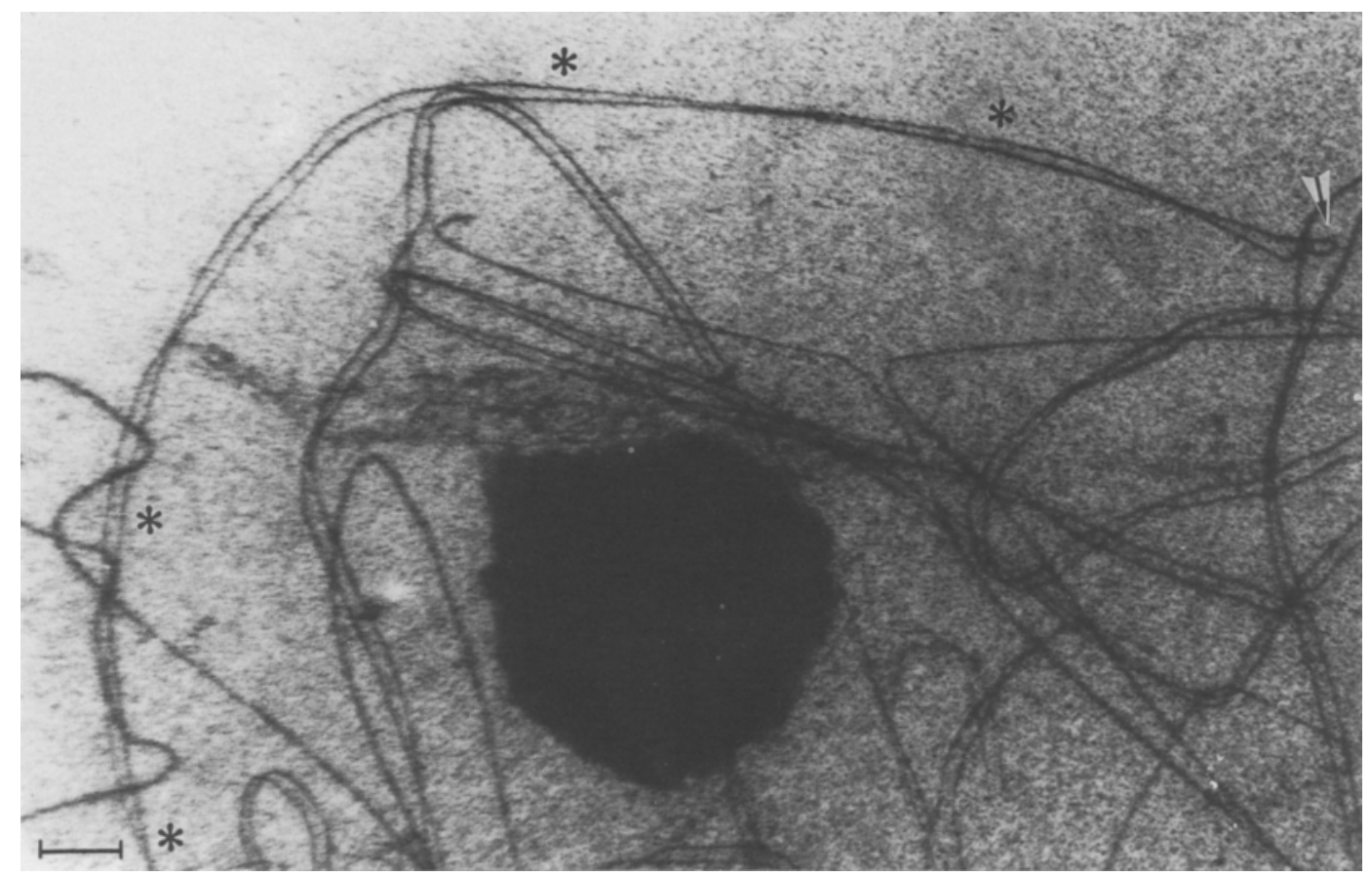

Figure 10. A micrograph showing a part of a foldback paired isochromosome for the long arm of chromosome $5 \mathrm{~B}$. The arrow denotes the end of the loop, where the lateral component folds back on itself. $($ Bar $=1 \mu \mathrm{m})$

Table IV. Synaptonemal complex (SC) length, the lateral component (LC) length of one complement ( $1 / 2 \mathrm{LC}$ length) and degree of pairing in 11 nuclei ranging in stage from late zygotene (LZ) through pachytene (P) to early diplotene (ED) in wheat monoisosomic for the long arm of chromosome 5B. s.d., standard deviation.

\begin{tabular}{llll}
\hline $\begin{array}{l}\text { Nucleus } \\
\text { number }\end{array}$ & $\begin{array}{l}\text { SC length } \\
\mu \mathrm{m}\end{array}$ & $\begin{array}{l}1 / 2 \text { LC length } \\
\mu \mathrm{m}\end{array}$ & $\begin{array}{l}\% \\
\text { Pairing }\end{array}$ \\
\hline LZ1 & 1383 & 2361 & 59 \\
LZ2 & 1629 & 2495 & 65 \\
LZ3 & 1082 & 1821 & 55 \\
LZ4 & 1065 & 2374 & 45 \\
LZ5 & 995 & 1966 & 51 \\
\hline Mean \pm s.d. & $1231 \pm 268$ & $2203 \pm 292$ & $56 \pm 8$ \\
\hline P1 & 1213 & 1923 & 63 \\
P2 & 980 & 2018 & 49 \\
ED1 & 706 & 1640 & 43 \\
ED2 & 785 & 2123 & 37 \\
ED3 & 1225 & 1831 & 67 \\
ED4 & 1121 & 1972 & 57 \\
\hline Mean \pm s.d. & $1005 \pm 221$ & $1918 \pm 167$ & $53 \pm 12$ \\
\hline
\end{tabular}




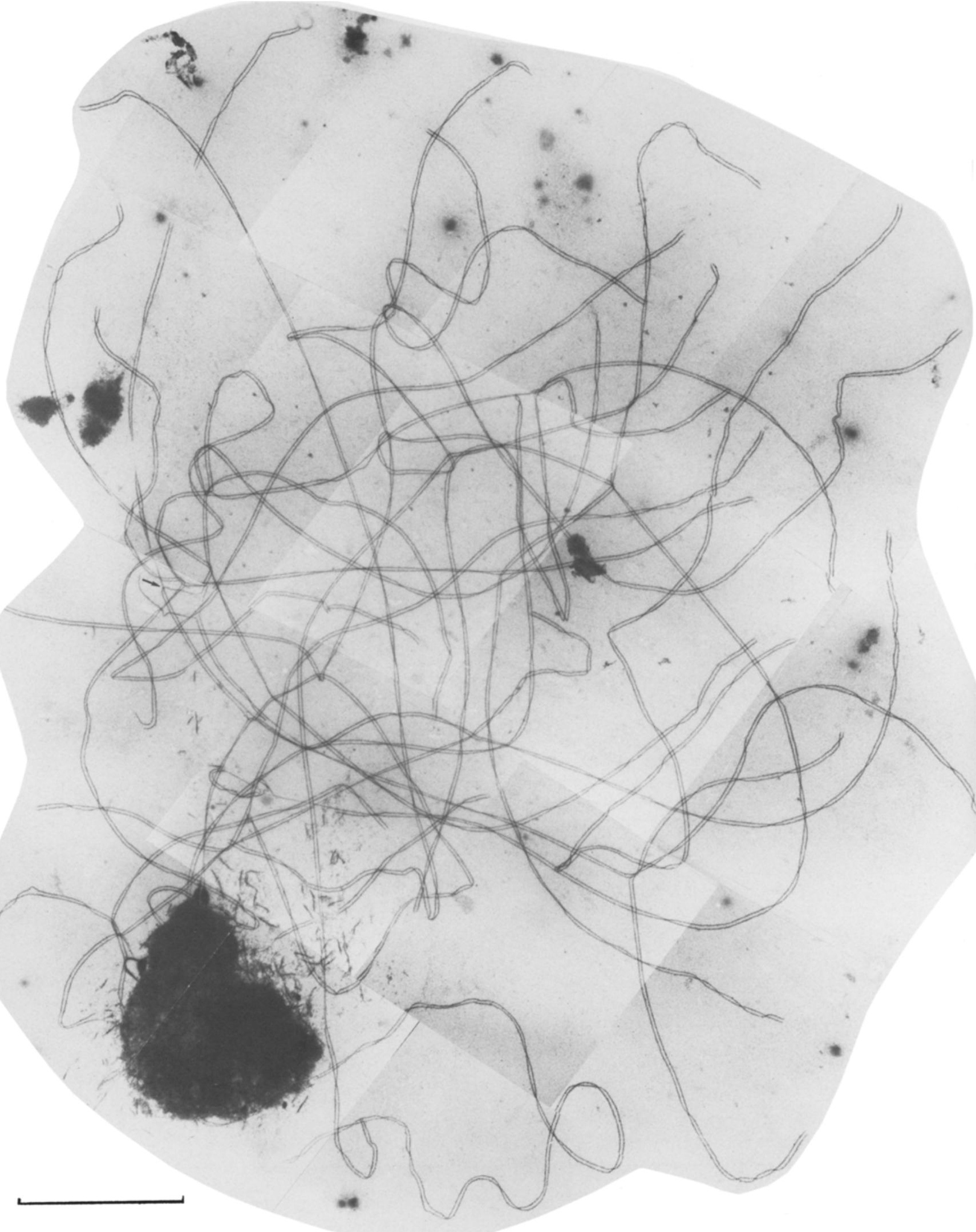


Figure 11. A montage of micrographs of a spread pachytene nucleus of the winter wheat variety, Vuka. An exchange of pairing partners is marked by the arrow. $(\mathrm{Bar}=10 \mu \mathrm{m})$

Chinese Spring as judged by a more frequent occurrence of this stage in the spreads of Vuka and Kraka wheat. However, as in Chinese Spring, all stages from late zygotene to early diplotene are often found in the three relatively synchronously developing anthers of a floret, indicating a very short pachytene stage. BEN. NETT et al. (1) thus estimated a duration of the pachytene stage of two hours in Chinese Spring wheat grown at $20^{\circ} \mathrm{C}$. As pachytene nuclei at the light microscopical level are difficult to distinguish from late zygotene or early diplotene nuclei, the actual duration of the pachytene stage may in fact be somewhat shorter.

The quantitative study of the winter wheats was only performed for the late zygotene to early diplotene interval and only data for the variety Vuka are presented. Electron microscopic analysis of spread microsporocytes of the variety Kraka, however, did not reveal obvious differences in the synaptic behaviour of the two varieties. Figure 11 is a montage of micrographs of a pachytene nucleus of the variety Vuka. Six nuclei, one late zygotene, four pachytene and one early diplotene nucleus were analyzed in detail (Table V). It is apparent that synapsis also in this variety is not complete, the mean degree of pairing in the six nuclei being $95 \%$. Inspection of several early diplotene nuclei also revealed unpaired segments. Exchanges in pairing partners were found in all the nuclei (Table V), whereas at metaphase $\mathrm{I}$, the complement was invariably present as bivalents. In general, the presence of unpaired segments could be attributed to interlocking or exchanges of pairing partners and different types of multiple associations were found in the different nuclei. A complex region of interchange is shown in Figure 12 and two multiple associations from the late zygotene nucleus are shown as tracings and as idiograms in Figure 13. The two micrographs and the idiogram in Figure 14 are from the early diplotene nucleus and show two regions with inverted pairing both located about $20 \mu \mathrm{m}$ from the end of the two heteromorphic bivalents.

The mean number of lateral components in multiple associations in the six nuclei of Vuka amounted to 6 with a range from 13 to 0 . This frequency is similar to that found in euploid Chinese Spring wheat at late zygotene (93\% synapsis) but ten times higher than that reported for Chinese Spring at pachytene, where a mean of only 0.6 lateral components per nucleus had pairing partner exchanges. Since the frequency of lateral components in multiple associations has not been investigated at earlier stages of

Table V. Synaptonemal complex (SC) length, the lateral component (LC) length of one complement ( $/ 2 \mathrm{LC}$ length) and degree of pairing in 6 nuclei ranging in stage from late zygotene (LZ) through pachytene (P) to early diplotene (ED) in the Danish winter wheat variety, Vuka. The numbers in parentheses are switch back associations of type II (see section 3.1.2 for explanation). s.d., standard deviation.

\begin{tabular}{lllll}
\hline $\begin{array}{l}\text { Nucleus } \\
\text { number }\end{array}$ & $\begin{array}{l}\% \\
\text { Pairing }\end{array}$ & $1 / 2$ LC length & $\begin{array}{l}\text { Number of LC's } \\
\text { in multiple associations }\end{array}$ \\
\hline LZ1 & 89 & 1516 & 13 & $(0)$ \\
P1 & 94 & 1691 & 3 & $(0)$ \\
P2 & 99 & 1608 & 6 & $(0)$ \\
P3 & 98 & 1430 & 4 & $(4)$ \\
P4 & 98 & 1434 & 7 & $(0)$ \\
ED1 & 94 & 1574 & 0 & $(0)^{\$}$ \\
\hline Mean \pm s.d. & $94 \pm 4$ & $1542 \pm 102$ & $6 \pm(1)$ \\
\hline
\end{tabular}

${ }^{s}$ Contains two chromosome pairs which appear to be heterozygous for inversions, see Figure 14. 


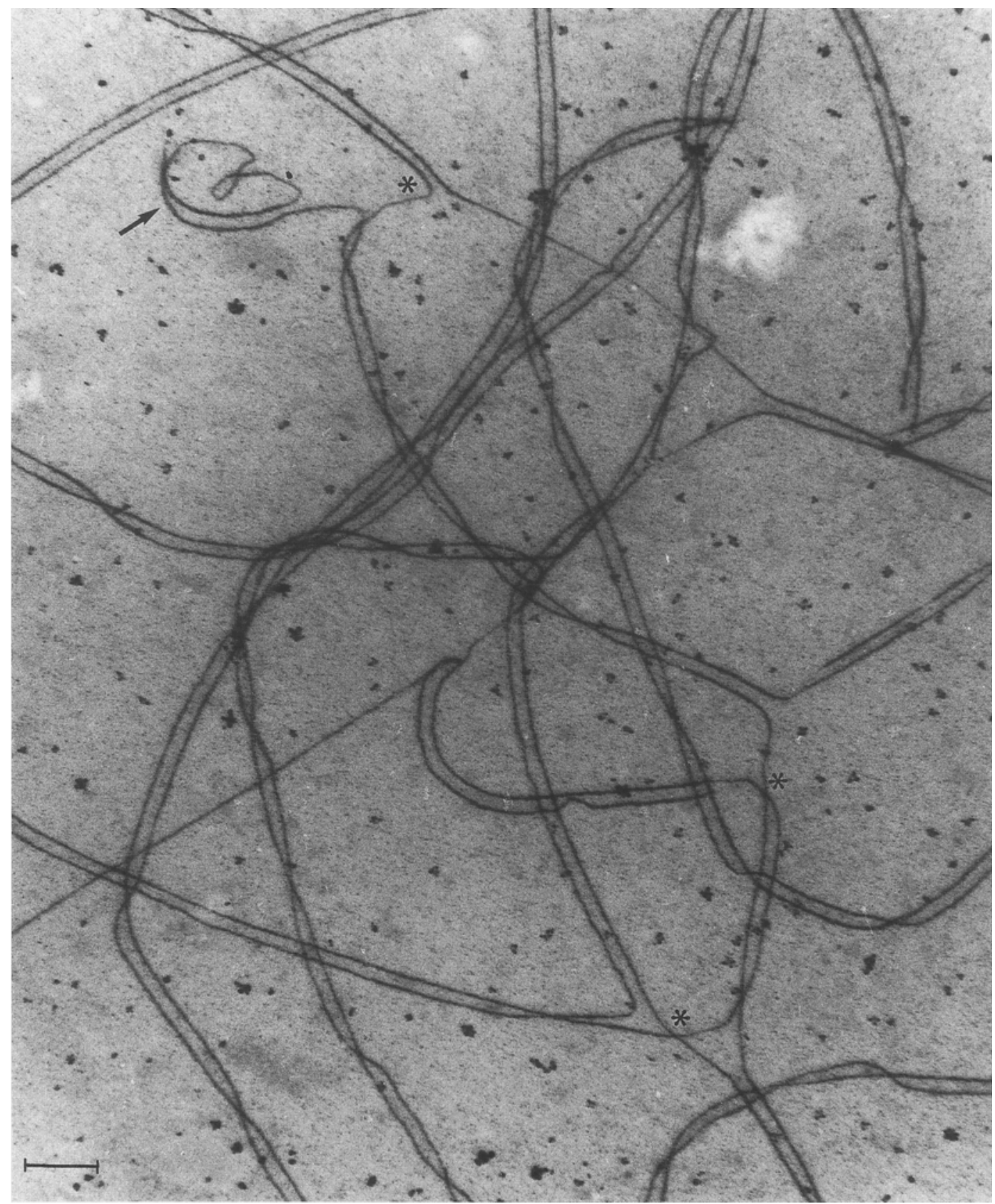

Figure 12. A micrograph showing examples of pairing partner exchanges at pachytene in the winter wheat variety, Vuka, denoted by asterisks. The arrow marks a region of foldback pairing. $(\mathrm{Bar}=1 \mu \mathrm{m})$

zygotene in Vuka it is unknown whether the different frequencies observed at pachytene reflect differences in the effectiveness of correction or differences in the initial number of multiple associations formed. 


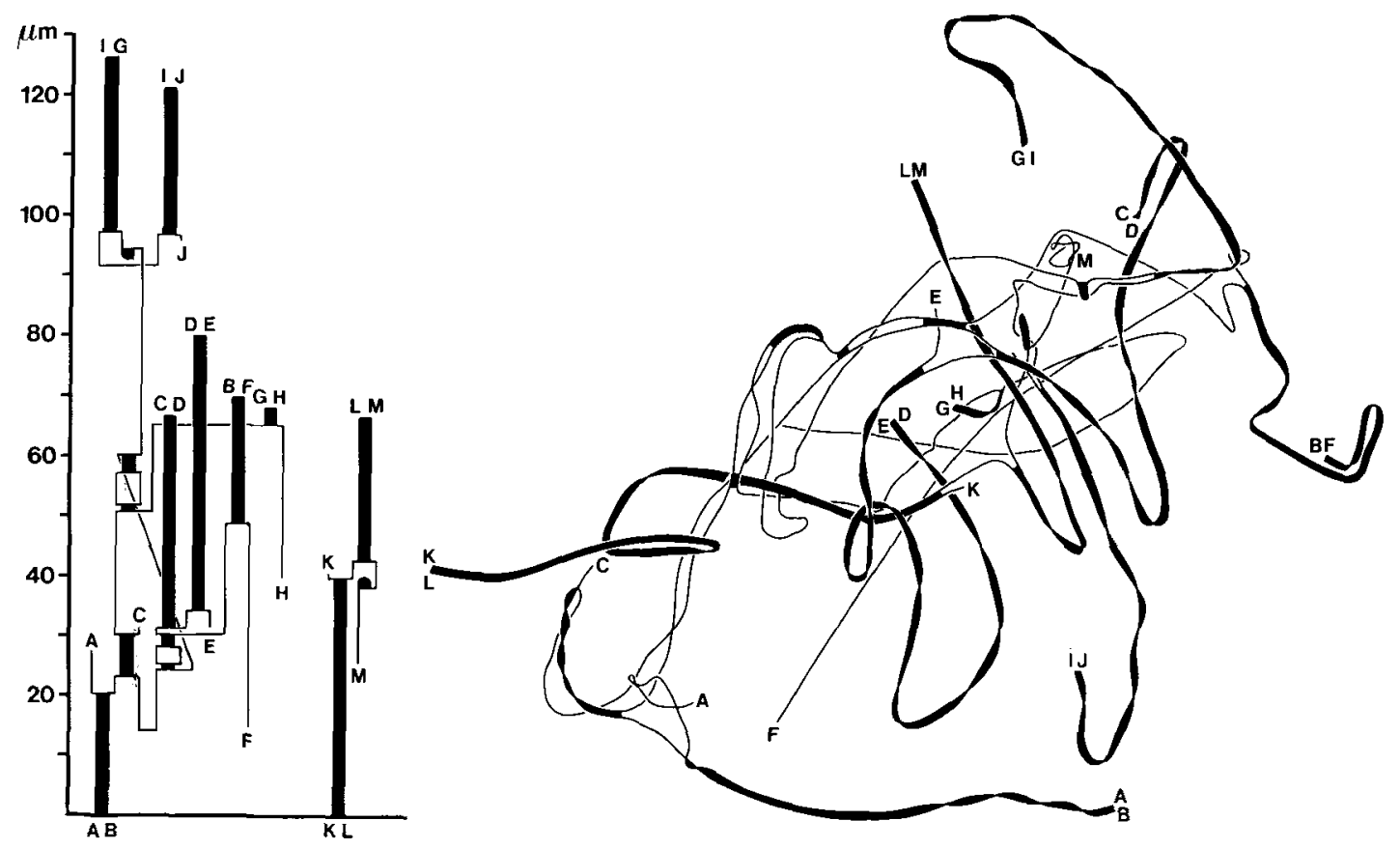

Figure 13. A tracing and diagrammatic presentation of a multiple association in a spread pachytene nucleus of the winter wheat variety, Vuka. See legends to Figures 4 and 5.

\section{DISCUSSION}

The following conclusions may be drawn from the present study.

1) Replacement of chromosomes $5 B$ with an isochromosome for the long arm of chromosome $5 \mathrm{~B}$ results in an arrest of synaptonemal complex formation when on the avarage $56 \%$ of the complement has synapsed. In contrast, synapsis comprises more than $90 \%$ of the complement in euploid wheat. As monoisosomic $5 \mathrm{BL}$ wheat in its genetic constitution differs from euploid wheat by the absence of the two short arms of chromosome 5B, it may be inferred that the short arm of chromosomes $5 \mathrm{~B}$ contains genes which somehow promote completion of synapsis.

2) In diisosomic 5BL wheat, where the two chromosomes $5 \mathrm{~B}$ have been replaced by two isochromosomes for the long arm of chromosome $5 \mathrm{~B}$, synaptonemal complex formation stops when on the average $40 \%$ of the complement has synapsed. The number of pairing partner exchanges is as low or even lower than in euploid wheat.

3) In spread nuclei of diisosomic 5BL wheat there is a more compact bouquet configuration than seen in euploid wheat. The bouquet is maintained into early diplotene in contrast to the situation in euploid wheat and wheat monoisosomic for 5BL where the bouquet disperses by a migration of the telomeres during zygotene.

4) The analysis of the two Danish winter wheat varieties, Vuka and Kruka has revealed that as in euploid Chinese Spring wheat pairing partner exchange and interlocking are regular events of the zygotene chromosome pairing. Synapsis is as in Chinese Spring wheat not complete and the pachytene stage short. These results provide a primary indication that meiosis in the cultivar Chinese Spring also at the ultrastructural level can be considered representative for other hexaploid wheat cultivars. 

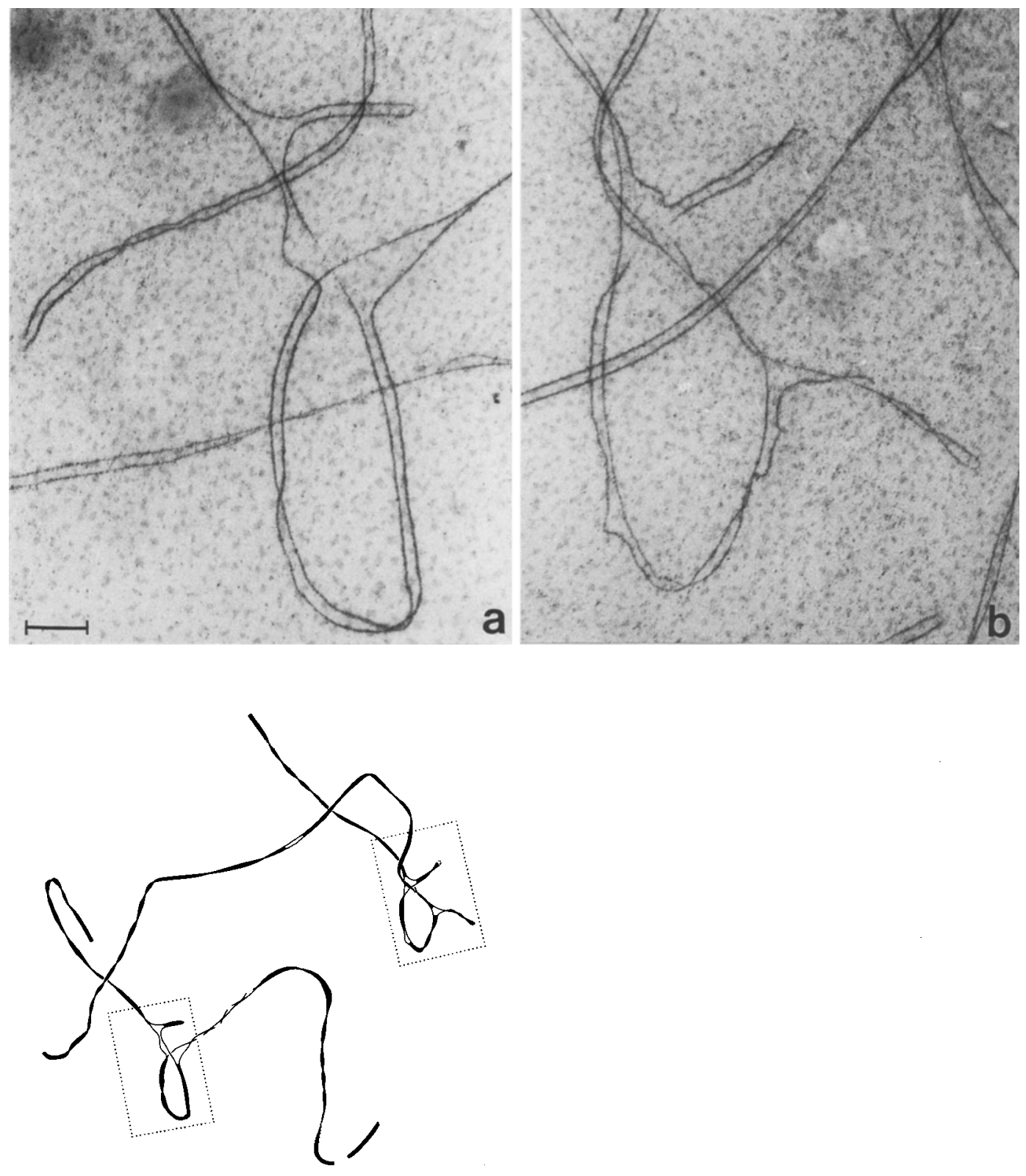

C

Figure 14. Micrographs of two regions of an early diplotene nucleus of the winter wheat variety, Vuka, showing pairing configurations indicative of inversion heterozygosity between the two involved chromosome pairs. A tracing of the two involved chromosome pairs is given in Figure $14 \mathrm{c}$. $(\mathrm{Bar}=1 \mu \mathrm{m})$ 


\section{ACKNOWLEDGEMENTS}

1 am indebted to Professor DITER vON Wettstein, M.Sc. Xingzhi Wang and Dr. SøREN W. RASMUSSEN for discussion and review of the manuscript. The expert technical assistance of Bibi Stampe ANDERSEn, Jean SAGE, Nina RasmusSEn and ANN-Sofi Steinholtz is gratefully acknowledged. The Royal Danish Academy of Sciences and Letters is thanked for having provided me with a Niels Bohr Scholarship. The work was also supported by grant BI6-E-168-DK from the Commission of the European Communities.

\section{REFERENCES}

1. BennetT, M.D. M.K. RaO, J.B.SMith \& M.W. BaYLISS: Cell development in the anther, the ovule and the young seed of Triticum aestivum L. var. Chinese Spring. Phil. Trans. R. Soc. Lond. B. 266, 39-81 (1973)

2. ENDO. T.R. \& B.S. GILL: Somatic karyotype, heterochromatin distribution, and nature of chromosome differentiation in common wheat, Triticum aestivum L. em Thell. Chromosoma (Berl). 89, 361-369 (1984)

3. Feldman, M: The effect of chromosomes 5B, 5D and $5 \mathrm{~A}$ on chromosomal pairing in Triticum aestivum. Proc. Nat. Acad. Sci. USA 55, 1447. 1453 (1966)

4. Feldman, M \& L. Avivi: Genetic control of bivalent pairing in common wheat: the mode of $\mathrm{Ph} 1$ action. Kew Chromosome Conf. III (in press) (1987)

5. Hовоцтн. P.: Chromosome pairing in allohexaploid wheat var. Chinese Spring. Transformation of multivalents into bivalents, a mechanism for exclusively bivalent formation. Carlsberg Res. Commun. 46, 129-173 (1981)
6. Holm, P.B.: Chromosome pairing and chiasma formation in allohexaploid wheat, Triticum aestivum analyzed by spreading of meiotic nuclei. Carlsberg Res. Commun. 51, 239-294 (1986)

7. Holm, P.B.: Chromosome pairing and synaptonemal complex formation in hexaploid wheat, monosomic for chromosome 5B. Carlsberg Res. Commun. 53, 57-89 (1988)

8. HoLM, P.B.: Chromosome pairing and synaptonemal complex formation in hexaploid wheat, nullisomic for chromosome 5B. Carlsberg Res. Commun. 53, 91-109 (1988)

9. HoLm, P.B.\& X. WANG: The effect of chromosome $5 B$ on synapsis and chiasma formation in wheat, Triticum aestivum cv. Chinese Spring. Carlsberg Res. Commun. 53, 191-208 (1988)

10. Jenkins, G.: Chromosome pairing in Triticum aestivum cv. Chinese Spring. Carlsberg Res. Commun. 48, 255-283 (1983)

11. KoNG, F.: Identification by $\mathrm{N}$-banding of isochromosomes for the long arm of chromosome $5 \mathrm{~B}$ in Triticum aestivum, cv. Chinese Spring. Cereal Res. Commun. 13, 321-328 (1985)

12. Riley, R., V. ChapMan, R.M. YOUNG \& A.M. BELFIELD: Control of meiotic chromosome pairing by the chromosomes of homoeologous group 5 of Triticum aestivum. Nature 212, 1475-1477 (1966)

13. WANG, $X$.: Chromosome pairing analysis in haploid wheat by spreading of meiotic nuclei. Carlsberg Res. Commun. 53, 135-166 (1988)

14. WANG. X.\& P.B. Holm: Chromosome pairing and synaptonemal complex formation in wheat-rye hybrids. Carlsberg Res. Commun. 53, 167-190 (1988)

15. WischmanN, B.: Chromosome pairing and chiasma formation in wheat plants triisosomic for the long arm of chromosome 5B. Carlsberg Res. Commun. 51, 1-25 (1986)

16. YaCobi, Y.Z., T. Mello-Sampayo \& M. Feldman: Genetic induction of bivalent interlocking in common wheat. Chromosoma 87, 165-175 (1982) 